\title{
Africa's jungle and the arch: Of elephants and CHIMPS
}

\author{
Lars G. Svensson, MD, PhD, Matthew Eagleton, MD, and Eric Roselli, MD
}

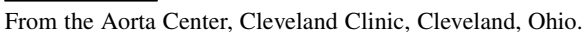

Disclosures: Lars G. Svensson, $\mathrm{MD}, \mathrm{PhD}$, holds a patent with potential royalties for an aortic valve and aortic root stent graft with connecting branch grafts to the coronary ostia. Eric E. Roselli, MD, is a consultant and investigator for Bolton, Gore, and Medtronic. Matthew Eagleton, MD, has nothing to disclose with regard to commercial support.

Received for publication June 24, 2016; accepted for publication June 27, 2016; available ahead of print Aug 5, 2016.

Address for reprints: Lars G. Svensson, MD, PhD, The Aorta Center, Cleveland Clinic, 9500 Euclid Ave, J1-227, Cleveland, OH 44195 (E-mail: svenssl@ccf.org).

J Thorac Cardiovasc Surg 2016;152:958-9

0022-5223/\$36.00

Copyright (c) 2016 by The American Association for Thoracic Surgery

http://dx.doi.org/10.1016/j.jtcvs.2016.06.046
}

In this issue, Zhang and colleagues ${ }^{1}$ present a case report describing the application of one of the novel endovascular CHIMPS (chimneys, periscopes, snorkels, sandwiches) methods for the aortic arch. In this particular area of the aorta, such procedures have acquired names related to African "jungle" fauna and flora. For example, terms that have been used for open arch operations include the calla inversion operation for aortic dissection (callas are a type of African lily), elephant trunk procedures, frozen elephant trunk endografts (frozen elephant and leopard carcasses have been found high in the snow belt of Kilimanjaro), and now the latest, endovascular CHIMPS. ${ }^{2-5}$

Initially, using graft-covered stents to maintain blood flow through an aneurysm sac was relatively easy, but when aorta interventionalists started tackling areas of branch arteries, where the blood flow and nutritional energy maintenance of vascular beds became vital, then other side-graft options had to be considered. Our late colleague, Roy Greenberg, ${ }^{6-8}$ was an early pioneer of a variety of parallel grafts: For example, a graft that Greenberg coined a "snorkel." Despite this, he essentially abandoned this approach in favor of fenestrated and branched endografts that incorporate either a hole or a directional branch onto the aortic component, which is then bridged to the target vessel with a covered stent. Various applications of the technique have been assigned names such as snorkel, chimneys, periscope, sandwich, and the acronym CHIMPS, depending on their configuration. Frank Criado $^{9}$ from our affiliate MedStar Union Hospital has attempted to classify these grafts by arrangement and length. Essentially, a snorkel stent lies next to an aortic stent and supplies a distal vascular bed, for example, a snorkel going to the left subclavian or the left carotid artery where their origins are covered by the aortic stent; a periscope takes the blood supply from the distal landing site of a stent and runs parallel back up toward an artery such as the left subclavian artery; a sandwich is when a branch artery is sandwiched between 2 consecutive stents, typically for a distance of $10 \mathrm{~mm}$ or more of overlap and goes, for

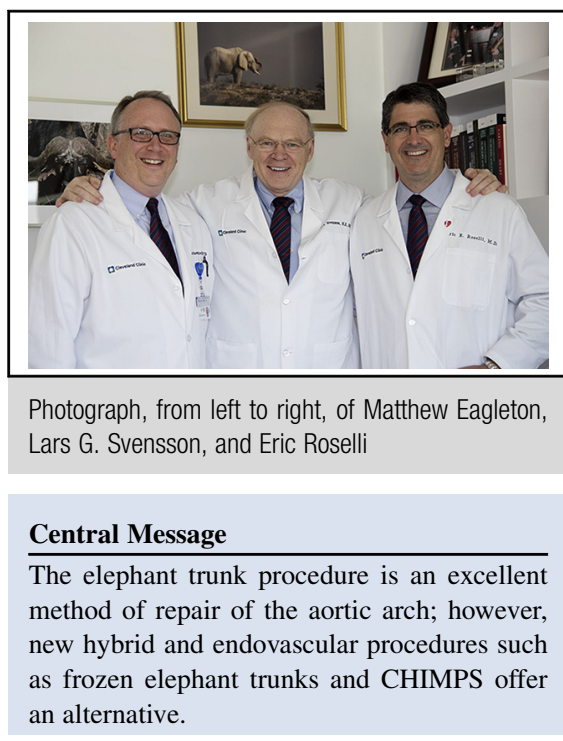

See Article page 1191.

example, to a visceral artery. There may be multiple branch grafts sandwiched between 2 stents. To add to the confusion, many have advocated these all be termed parallel grafts.

The ongoing challenge with these types of parallel grafts (CHIMPS) are the so-called gutter leaks that tend to occur in between the sandwich grafts. Indeed, Dr Greenberg (even though he coined the term snorkel) was rather cautious with regard to the CHIMP concept and ascertained that the future lay with the use of either fenestrations or connecting grafts directly from aortic stents to vascular beds. Perhaps the main challenge with the fenestrated and branched endografts is that they take a considerable time to make, predominantly due to the customization performed for each patient. For example, for the thoracoabdominal aorta, the time to manufacture is some 6 to 8 weeks. Other problems include the high cost, and that the method often requires a day to insert, with high risks involved.

For a technique to be widely adopted, the endovascular procedure (as with heart valve procedures), needs to be (1) easy to do, (2) safe, (3) have good early hemodynamics, and (4) have long-term durability. Straight stents are easy to insert and widely adopted, and CHIMPS are an easier compromise to overcome the challenges of doing more definitive spiral branch graft stents for the thoracoabdominal aorta or direct-connecting branch stents from an aortic stent in the arch. An important caveat is that the blood supply maintenance and long-term durability may not be adequate. 
The paper by Zhang and colleagues ${ }^{1}$ illustrates the interesting combination of CHIMPS in a patient with Marfan syndrome who refused surgery for an aortic arch dissection. Certainly, the images they provide show what can be achieved as an alternative to the elephant trunk procedure. This patient is young and will need a durable operation. Unfortunately, in our experience over time, we have observed that these CHIMPS procedures tend to break down and leak into the arch, including the arch actually rupturing. In addition, both clinical experience and bench-top testing have demonstrated a high rate of stent fractures when these devices are used in these configurations in the volatile jungle-like conditions of the proximal aorta. The combination of both dissection and anticoagulation for a mechanical valve will require intensive monitoring in these patients. Furthermore, as a general rule, patients with Marfan syndrome are young with fragile tissues, prone to progression of aneurysm formation, and are not good candidates for stenting, as are also patients with Loeys-Dietz and Ehlers-Danlos syndromes. This is particularly true when patients with connective tissue disease have survived an aortic dissection. ${ }^{10}$

In these latter patients, we believe, when feasible, it is much better to repair the arch with open surgery and ensure good blood flow to the organs to provide energy nutrition and long-term durability. For African wildlife managers, there are 4 tools for establishing a restorancy of game and habitat: Control of energy (fire), water, off-take, and fences. ${ }^{2}$ Similar to Africa, fences with leaks through gutters is not a long-term solution. Indeed, in our ${ }^{11}$ prospective trial of total arch replacements, of which $39 \%$ were reoperations and $61 \%$ were done with an elephant trunk procedure, survival was $99 \%$ and the stroke rate was $0.8 \%$. Thus, the results with elephant trunk procedures can be very good. The frozen elephant trunk, a hybrid procedure using both open techniques, like cardiopulmonary bypass with antegrade brain perfusion and endovascular devices fixed in place by the radial force of stents, harnesses the advantages of both strategies and has also been performed with very good results. Nevertheless, further engineering iterations of CHIMPS may address the problem with gutter leaks and become an alternative to the elephant trunk procedure for those patients who are at particularly high risk.

\section{References}

1. Zhang H-W, Fan K-J, Liang H-M, Hu J. Chimney and sandwich stent grafts for hybrid repair of type A dissection late after a Bentall for Marfan syndrome. J Thorac Cardiovasc Surg. 2016;152:1191-3.

2. Lytle BW, Svensson LG. A Short Safari Adventure among Africa's Thorny Bushveld Wildlife: History Guide, Life's Imperatives, Enigmas and Travel. Vol 1. Digital Publishers Group; 2013.

3. Sakamoto T, Yoshida T, Sugano T, Kudoh A, Susuki A. Simplified technique for hemi-arch replacement during open distal anastomosis: the "calla" method. Ann Thorac Surg. 1996;61:1021-3.

4. Svensson LG, Rushing GD, Valenzuela ES, Rafael AE, Batizy LH, Blackstone EH, et al. Modifications, classification, and outcomes of elephant-trunk procedures. Ann Thorac Surg. 2013;96:548-58.

5. Roselli EE, Subramanian S, Sun Z, Idrees J, Nowicki E, Blackstone EH, et al Endovascular versus open elephant trunk completion for extensive aortic disease. J Thorac Cardiovasc Surg. 2013;146:1408-16.

6. Greenberg RK, Clair D, Srivastava S, Bhandari G, Turc A, Hampton J, et al Should patients with challenging anatomy be offered endovascular aneurysm repair? J Vasc Surg. 2003;38:990-6.

7. Roselli EE, Greenberg RK, Pfaff K, Francis C, Svensson LG, Lytle BW Endovascular treatment of thoracoabdominal aortic aneurysms. J Thorac Cardiovasc Surg. 2007;133:1474-82.

8. Eagleton MJ, Follansbee M, Wolski K, Mastracci T, Kuramochi Y. Fenestrated and branched endovascular aneurysm repair outcomes for type II and III thoracoabdominal aortic aneurysms. J Vasc Surg. 2016;63:930-42.

9. Criado FJ, Duson S. Parallel grafts in perspective: definitions and a new classification [editorial comment]. Vascular Dis Manage. 2012;10:E16-9.

10. Roselli EE, Idrees JJ, Lowry AM, Masabni K, Soltesz EG, Johnston DR, et al Beyond the aortic root: staged open and endovascular repair of arch and descending aorta in patients with connective tissue disorders. Ann Thorac Surg. 2016;101:906-12.

11. Svensson LG, Blackstone EH, Apperson-Hansen C, Ruggieri PM, Ainkaran P, Naugle RI, et al. Implications from neurologic assessment of brain protection for total arch replacement from a randomized trial. J Thorac Cardiovasc Surg. 2015;150:1140-7.e11. 